\title{
TRAFFIC VOLUMES TEST OF AIRPORT RUNWAY
}

\author{
Xingang Shi, Liangcai Cai and Guanhu Wang
}

\author{
University of Air Force Engineering, Department of Airport Construction Engineering, \\ Xi'an,China; kgdwxsxg@163.com,994174763@163.com,794599756@qq.com
}

\begin{abstract}
Currently, airport pavement design only considers the different horizontal standard deviation at the end and the middle of the runway, which had ignored the longitudinal distribution of airport runway traffic volume (ARTV). Especially for short take-off and landing aircraft, the take-off and landing distribution are not full of the whole runway. In allusion to the characteristics of ARTV, this paper developed a test system for the wheel track distribution and conducted a test of a short take-off and landing aircraft. Based on the statistics and analysis of test results, the horizontal and longitudinal distribution statistical laws of ARTV were obtained. At last, the longitudinal passage factor was proposed, and the planar distribution model was established to evaluate the ARTV at each point of the runway. By comparison with current design specifications, it is indicated that the pavement thickness will be designed more conservative without considering the planar distribution of traffic volumes.
\end{abstract}

\section{KEYWORDS}

Airport, Pavement design, Traffic volume, Planar distribution, Influence factors

\section{INTRODUCTION}

The design of a new runway requires information on many parameters: including airport runway traffic volume (ARTV), coverage and pass-to-coverage ratio, mixed traffic analysis if there is more than one significant aircraft and design life. Among all the parameters, ARTV was defined as number of aircraft wheel passes the pavement [1]. In the beginning, the ARTV model was simplified as the uniform distribution [2]. As early as the late 1950s, the USA Air Force had carried out tests on ARTV. Based on the test data, it was suggested that the airplane wheel tracks were uniformly distributed in the 1/3 width range of the middle runway [3]. In 1960, Vedros, professor of USA Army Engineering Laboratory, put forward the Pass-to-coverage ratio to build the uniform distribution model, which was widely recognized and concerned [4]. The field survey results of aircraft distribution in Buffalo International Airport and Atlanta International Airport [5][6] shown that the APTV model was better fitted by a normal distribution.

Review of the pavement design methods in various countries, different considerations were given to the lateral distribution of ARTV. Airport Pavement Structural Design System in Australia suggested that the transverse distribution standard deviations of wheel track were $1.8 \mathrm{~m}$ to $3.4 \mathrm{~m}$, $0.8 \mathrm{~m}$ to $1.8 \mathrm{~m}$ and $2.4 \mathrm{~m}$ to $3.2 \mathrm{~m}$ in runway, taxiway and connection lane, respectively [7]. In 2003 Boeing, in conjunction with FAA, conducted the B747 aircraft wheel track lateral offset tests using laser testing technology at New York's Kennedy International Airport and Anchorage International Airport [8][9]. According to the results of previous tests, the standard deviation of transverse distribution was determined as 30.435 inch $(773 \mathrm{~mm}$ ) in FAA consultation bulletin (150/5320-6E) [10]. The specification revised in 2016 (AC 150/5320-6F) also adopted the same distribution model [11] [12]. It is assumed that the lateral distribution of wheel tracks is standard Beta distribution in 
the Guideline on PCN Assignment of Netherlands [13]. The wheel tracks standard deviations of take-off and landing are recommended as $2.4 \mathrm{~m}$ and $2.6 \mathrm{~m}$ for $45 \mathrm{~m}$ runway width, $2.4 \mathrm{~m}$ and $3 \mathrm{~m}$ for $60 \mathrm{~m}$ runway width. In the pavement design guidelines for Japanese airports, the distribution of front landing gear in the cross direction of runway is classified according to the design load. The range of runway standard deviations for take-off and landing are $0.42 \mathrm{~m}$ to $0.91 \mathrm{~m}$ and $1.31 \mathrm{~m}$ to $1.74 \mathrm{~m} \mathrm{[14]} \mathrm{[15].}$

In China, Multiple aircraft wheel tracks had been recorded by Lu and Wang, suggesting the normal distribution of APTV [16] - [18]. The newly revised asphalt pavement design in China (MH/T 5010-2017) [19] also adopted the same distribution model as FAA. Normal distribution of APTV was more suitable in coverage calculation than uniform distribution based on the research of $\mathrm{Li}$ and Lin [20][21]. Lei [22][23] conducted a comprehensive comparison of the lateral distribution test systems including infrared, video, piezoelectric and laser. Finally, laser testing technology was determined to carry out the lateral offset tests in Hongqiao Airport. The measured results showed that the wheel track distribution obeys a negative skew distribution with a mean value of $0.17 \mathrm{~m}$ and a standard deviation of 0.99. Furthermore, Shi et al. [24][25] used the used the test statistical results for the pavement response study. It can be seen from the above reviews that in the field of pavement thickness design [26], runway width design [27] and pavement remaining life prediction [28], the lateral distribution of APRV had been widely used.

The distribution of ARTV evolved from uniform to normal, which declared the method progressed from "point" to "line". However, it is quite clear that ARTV could not bestrew the whole runway especially for military aircraft using both sides and whose taking off distance was less half of the runway. There is not only lateral distribution in the ARTV, but also longitudinal distribution due to different take-off and departure spots, landing locations and aircraft sideslips, especially for short take-off and landing aircraft. There is limited information in literatures describing the longitudinal distribution of APRV. This paper developed a test system for the wheel track distribution and conducted a test of a short take-off and landing aircraft. Then based on the statistics and analysis of test results, the horizontal and longitudinal distribution statistical laws of ARTV were obtained. The planar distribution model was established to evaluate the ARTV at each point of the runway, which provided a new method for the description of APTV.

\section{CHARACTERISTICS OF ARTV}

Compared with the traffic volume of highway, the ARTV has the following characteristics: First, ignoring the influence of short-distance acceleration, it is approximated that speed and load of the vehicle are constant when driving in the lane. That is, the motion states of vehicles in different cross-sections are unchanged. However, the lift of an aircraft is subject to changes in speed, resulting in loads variation acting on different cross-sections. Second, the road traffic volume is calculated by the direction coefficient, the lane coefficient and the vehicle type distribution coefficient. The distribution coefficient is constant, that is, the vehicle wheel track is assumed to be evenly distributed in the lane. The ARTV is calculated by multiplying the traffic coverage rate and the number of traffic passes. The traffic coverage rate reflects that the statistical law of the wheel track in the cross section, which obeys the normal distribution. Besides, same state of motion and same distribution of traffic volume is assumed when the vehicle is driving in the lane, while the lateral standard deviation of ARTV has changed because of the aircraft taking off offset the runway centerline, and landing alignment the runway centerline. Last but not least, the road traffic volume is constant in the longitudinal direction, while the ARTV in longitudinal direction is different due to diversification in aircraft take-off starting position, take-off running distance, landing grounding point position, and landing slip. However, the traffic volume distribution is similar to the highway traffic volume distribution in the taxiway, connecting lane, towing lane and tarmac, etc. 
From above analysis, there are different traffic volumes in every point of the runway. In fact, the characteristics of ARTV consist of lateral and longitudinal distributions. The current specification only considered the lateral variance. Longitudinal distribution had been simplified as the different offset standard deviations at the edge of the runway and the middle of the runway. It is necessary to consider the longitudinal traffic distribution in pavement design.

\section{ARTV TEST}

\section{Test methods and principles}

Distance measuring techniques including infrared, video, piezoelectric and laser had been used to capture the wheel-track of the aircraft [22][23]. Infrared ranging method is that the transmitter sent infrared beam and when the wheels pass through cutting the beam, receivers cannot receive the infrared signal to trigger the event and record the wheel track position. It is clear that the infrared ranging method has the advantages of high propagation speed and low cost. However, the receiving and transmitting devices of the system are arranged at a long distance, and the system has poor anti-interference ability. Besides it is difficult to measure the offset of the complex axial type, and the test accuracy is greatly affected by the environment. The video test technology arranges high-speed cameras at the end of the runway to capture the position of the landing point. And the distribution of the wheel trace was obtained by analyzing the video images. Thus, the system is easy to install, simple to maintain, and intuitive to process the test results, while there are also high requirements for the camera, high cost, and heavy data processing task. What more, it is hard to extract of the landing point accurately. Pressure sensors or distributed optical fiber sensors were deployed under the pavement to measure the pavement response by Piezoelectric testing technology. The use of piezoelectric testing technology to test aircraft wheel tracks has low cost and high precision. But there are also defects such as large pre-distribution of the sensor and difficulty in repairing once damaged. Laser testing technology use laser transmitter to transmit laser beam. When the wheel passes by, the laser reflects, and the receiving device receives the echo signal. The distance between the wheel and the rangefinder is calculated by the product of wave velocity and time difference. This method has stable performance, strong antiinterference, simple adjustment, high precision and moderate cost. The paper intends to use laser testing technology to measure the APTV.

\section{Laser test system}

As shown in Figure 1, the laser test system consists of five parts: laser ranging sensor, data storage unit, visible laser calibration device, instrument stents and power supply unit. The system adopts FSA-ITS02 laser sensor, produced by Shenzhen Lanshi Laser Radar Co., Ltd. The test accuracy of the system can reach $5 \mathrm{~cm}$ and the measuring frequency is $2 \mathrm{kHz}$ to $4 \mathrm{kHz}$. It can trigger the measurement of high-speed moving objects within $120 \mathrm{~m}$ range. In order to meet the requirements of high-frequency acquisition and recording, industrial-grade serial data recorder produced by Shenzhen Jingmei Technology Co., Ltd was employed. The data transmission rate can reach $921600 \mathrm{bps}$. After power-on, the trigger data will be stored in an SD card. The calibration system is a DANGER laser pointer which emits visible laser light before measurement to ensure perpendicularity between the test system and the runway. The power supply unit is a $12 \mathrm{~V} / 60 \mathrm{~A}$ lithium battery, which can work continuously for 48 hours. The instrument bracket is made of aluminium alloy, which can provide sufficient support strength and reduce the weight of the equipment to facilitate equipment transportation and installation. The height of the sensor can be $75-100 \mathrm{~cm}$. The pitch angle of the device can be adjusted from $-45^{\circ}-45^{\circ}$. 


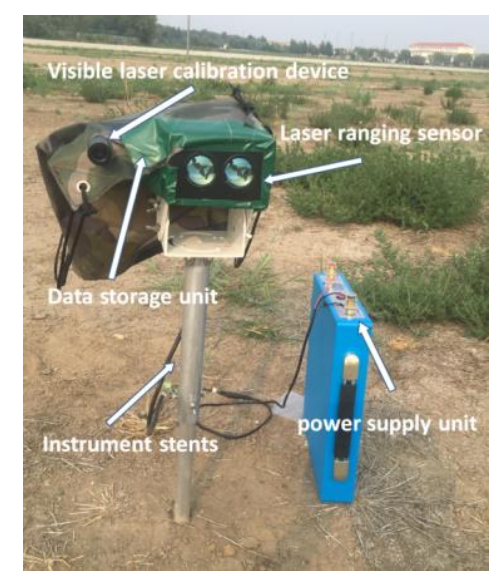

Fig. 1 - Field installation of test equipment

\section{Test scheme}

\section{Test Profile and device arrangement}

The test site was selected at an airport in Tianjin, whose runway length is $2800 \mathrm{~m} \times 60 \mathrm{~m}$. The wheel track test of aircraft A was carried out according to the flight plan. A total of 436 flights were recorded. During the test period, more southerly winds were observed at the test site, so the north end of the runway was the main take-off and landing direction. The equipment was arranged at the north end of the runway according to the following principles:

The laser ranging device was arranged in the flat area on one side of the runway. The distance from the instrument to the center line of runway meet the flight safety requirements, which is generally not less than $60 \mathrm{~m}$. In order to avoid the bird-riding vehicle passage and the other inconvenient installation area, the distance from the equipment to the runway center line ranged from $63.2 \mathrm{~m}$ to $93.3 \mathrm{~m}$. Layout distances of all test equipment are shown in Table 1. The longitudinal layout distance was arranged according to the principle that half of the runway should be covered, the landing site at the end of the runway and the take-off site in the middle of the runway should be densely arranged, and the taxiing region should be appropriately sparse. the test area of $1285 \mathrm{~m}$ was divided into three parts:

(1) Landing region: the initial position was $191 \mathrm{~m}$ away from the end of the runway, and 6 instruments were installed in total, covering the landing area. (2) Middle taxiing region: a total of 5 sets of equipment were installed in the high-speed taxiing area; (3) Take-off region: a total of 6 instruments were installed to cover the take-off position of the test aircraft.

Tab. 1 - Layout distances of all test equipment

\begin{tabular}{|c|c|c|c|c|c|c|c|c|c|}
\hline Device number & 1 & 2 & 3 & 4 & 5 & 6 & 7 & 8 & 9 \\
\hline $\begin{array}{c}\text { Distance from the centerline of the } \\
\text { runway }(\mathrm{m})\end{array}$ & 72.2 & 73.5 & 78.2 & 78.6 & 82.7 & 82.9 & 83.1 & 87.8 & 63.2 \\
\hline $\begin{array}{c}\text { Distance from the end of the runway } \\
(\mathrm{m})\end{array}$ & 191 & 239 & 277 & 368 & 430 & 483 & 562 & 652 & 740 \\
\hline $\begin{array}{c}\text { Device number } \\
\text { Distance from the centerline of the } \\
\text { runway (m) }\end{array}$ & 87.8 & 88.8 & 88.5 & 89.01 & 90.9 & 91.3 & 92.2 & 93.3 & \\
\hline $\begin{array}{c}\text { Distance from the end of the runway } \\
(\mathrm{m})\end{array}$ & 814 & 881 & 972 & 1036 & 1101 & 1165 & 1222 & 1285 & \\
\hline
\end{tabular}




\section{Installation Steps}

(1) Hammer the bracket and wedge it into the soil foundation in the flat area. Install the fixed laser ranging sensor, ensure the sensor slope is 0 (Figure $2(a)$ ).

(2) The tester holds the self-made equipment debugging board (Figure 2(b)), stands near the centerline of the runway, and debugs the vertical line of the runway. The other tester turns on the calibration laser pointer and adjusts the height of the device so that the visible laser projection point is $25 \pm 5 \mathrm{~mm}$ above the center of the runway (Figure 2(c)).

(3) Adjust the angle of the sensor from left to right to make laser projection move around the debugging board. When the sensor reading is at the minimum, the device is perpendicular to the middle line of the runway (Figure 2(d)).

(4) Install the memory card after power off and then restart to conduct the test (Figure 2(d)).

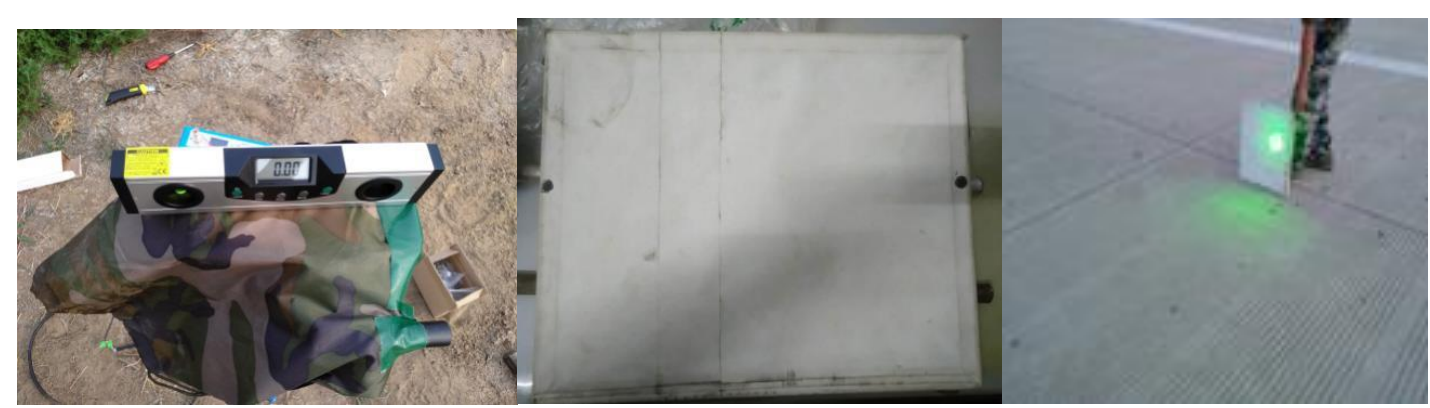

(a)

(b)

(c)

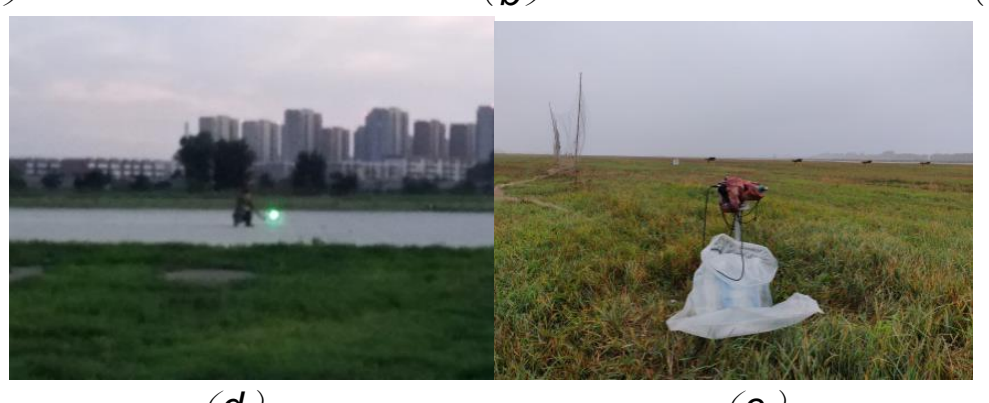

(d)

(e)

Fig. 2 - Installation step

\section{LATERAL STATISTICAL REGULATION OF APTV}

The Cartesian coordinate system was setup at the mid-point of the runway edge. $x$-direction is along the lateral edge of the runway, and $y$ - direction is along the center line of the pavement. Figure 3 illustrates the coordinate system.

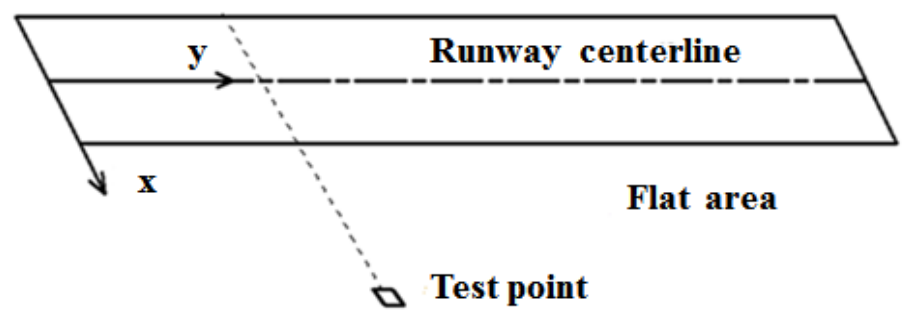

Fig. 3 - Coordinate system of the planar distribution model

The runway was divided into groups along $x$ direction with the interval of $2 \mathrm{~m}$ length. And the coverage of each group was counted divided into the states including landing, single-aircraft take-off and double-aircrafts take-off (two fighter jets taking off at the same time, side by side). 
Figures below show the horizontal distribution of APTV during landing recorded by equipment No.7 and No.14.
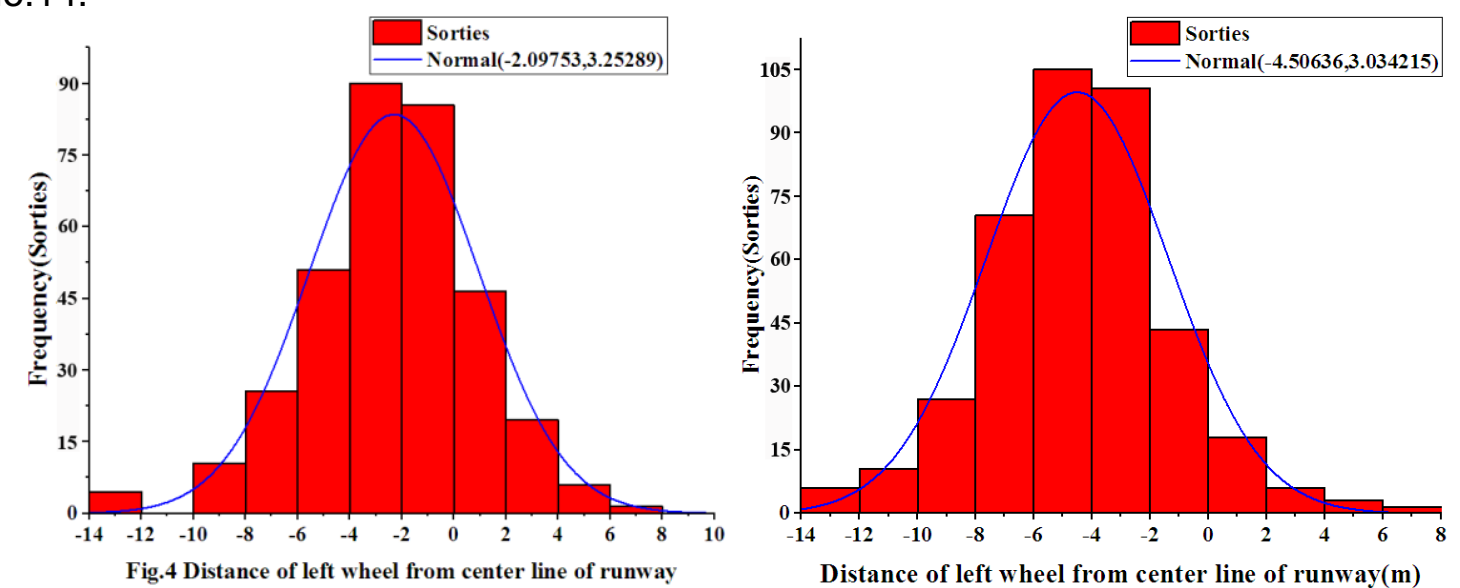

Fig. 5 - Lateral distribution histograms and fitting curves of landing wheel track by equipment No. 7 and equipment No.14, respectively

As can be seen from the Figure 5, 333 aircraft passes through equipment No. 7 . The test results have an average value of $-2.290 \mathrm{~m}$ and a standard deviation of $3.253 \mathrm{~m}$. Equipment no. 14 tested 357 sets of data, with an average value of $-4.506 \mathrm{~m}$ and a standard deviation of $3.034 \mathrm{~m}$. The frequency distribution histograms of the two groups were found to have good normality fitting. What is more the k-s test showed that the wheel offset of all the two sections follow the normal distribution.

\section{Track volume for landing}

The landing track volumes of the 17 groups were analyzed by the same statistical and hypothesis-test method. The equation and curve shown in Figure 5 were obtained by fitting the variation of the mean and standard deviation in y direction.
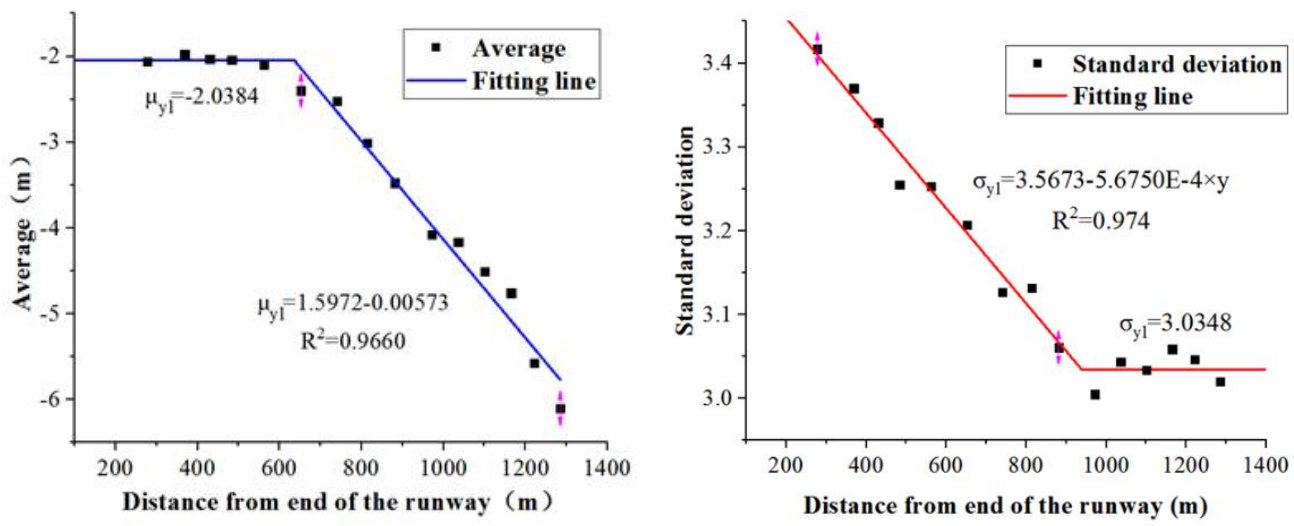

Fig. 5 - Mean value and standard deviation in y direction for landing track volume

The landing wheel coverage recorded by equipment No. 1 was only 49 times. There are insufficient data to acquire the statistics regulation of the cross section. From Figure 5, the average values of equipment from No. 2 to No. $7,-2.0385$ was used to illustrate the beginning average. Average value from No. 8 to No. 17 decreased as the aircraft slowed down and deviated from the 
runway centerline. It can also be seen from Figure 5 that the standard deviation decreased constantly after landing, as the aircraft aligned with the runway centerline. Besides, when the aircraft pass through equipment No. 12, the standard deviation maintained a constant. The variation mean value $\mu_{y l}$ and standard deviation $\sigma_{y l}$ were represented by the following piecewise functions.

$$
\begin{aligned}
& \mu_{y l}=\left\{\begin{array}{cc}
-2.0385, & 0 \leq y \leq 634.5 \\
1.5972-0.00573 y, & 634.5<y \leq 2500
\end{array}\right. \\
& \sigma_{y l}=\left\{\begin{array}{cc}
3.5673-5.6750 \times 10^{-4} \times y, & 0 \leq y \leq 938.3 \\
3.0348 \quad & 938.3<y \leq 2500
\end{array}\right.
\end{aligned}
$$

The above track value of landing refers to the outside edge of the main landing gear wheel. The average track value at the center of a wheel needs to add half of the width of the wheel, while the standard deviation remains unchanged.

$$
f_{x l}(x, y)=\frac{1}{\sigma_{y l} \sqrt{2 \pi}} e^{-\frac{\left(x-\mu_{y 1}+w / 2\right)^{2}}{2 \sigma_{y l}^{2}}}
$$

Where, $W$ is the width of the wheel.

\section{Track volume of single-aircraft take-off}

The same Analysis was used to process the horizontal deviation statistical data of single take-off wheel track. The fitting equation and curve shown in Figure 6 were obtained by statistical analysis of mean value and standard deviation of single take-off wheel track.
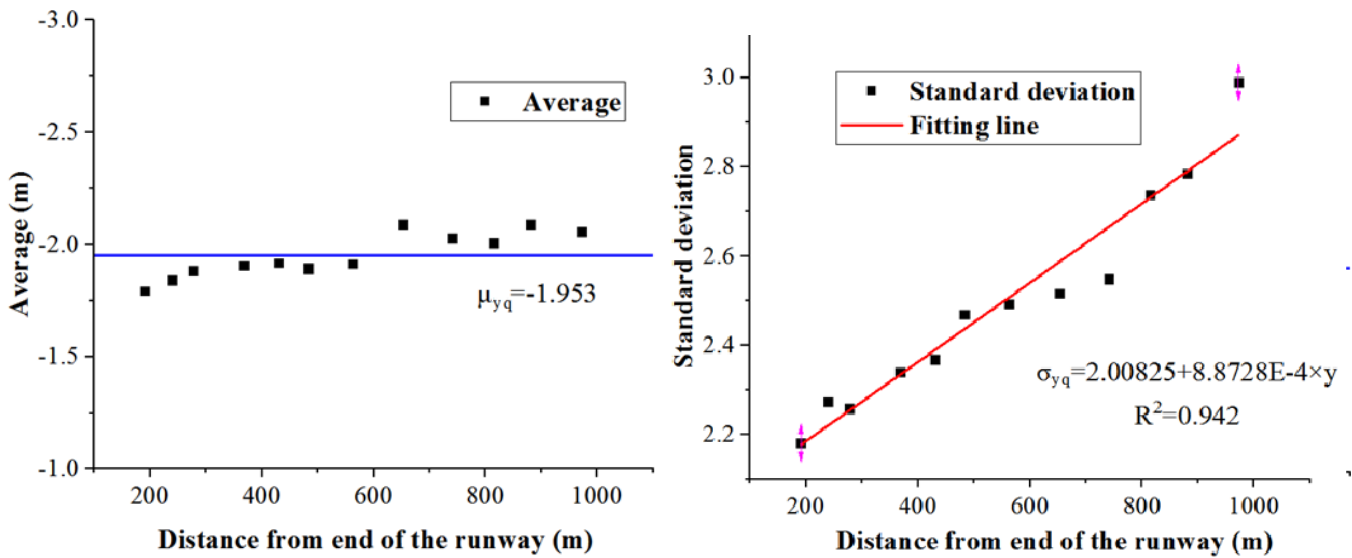

Fig.6 - Mean value and standard deviation in y direction for single-aircraft take-off track volume

The single take-off wheel coverage recorded by equipment No. 13 to No.14 was not more than 50 times. There are not enough data to acquire the statistics regulation of these cross sections. As shown in Figure 6, the average values of equipment No. 2 to No. 7 float around -1.9 $\mathrm{m}$. Mean value of the average, -1.953 was used to illustrate the average. Besides, with the increase of the flight distance, the standard deviation of the take-off wheel-track increases gradually. Following formula (6) exhibited good linear fit between standard deviation and ycoordinate.

$$
\mu_{y q}=-1.953
$$




$$
\sigma_{y q}=2.00825+8.8728 \times 10^{-4} \times y
$$

The wheel-track distribution of the middle point of the main landing gear on one side near the flat area can be expressed as

$$
f_{x q}(x, y)=\frac{1}{\sigma_{y q} \sqrt{2 \pi}} e^{-\frac{\left(x-\mu_{y q}+0.106\right)^{2}}{2 \sigma_{y q}^{2}}}
$$

\section{Track volume for dual-aircrafts take-off}

Same methods were used to analysis the take-off track volumes of two aircrafts. Figure 7 displays the fitting equation and fitting curve.
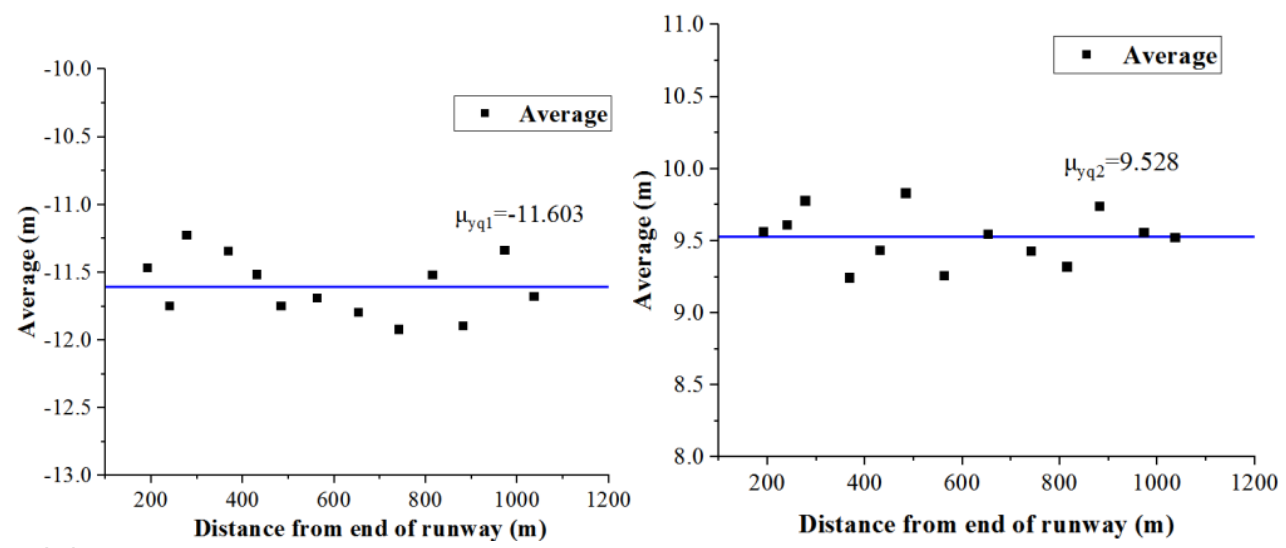

(a) Fitting equation and curve of mean values for left and right take-off tracks

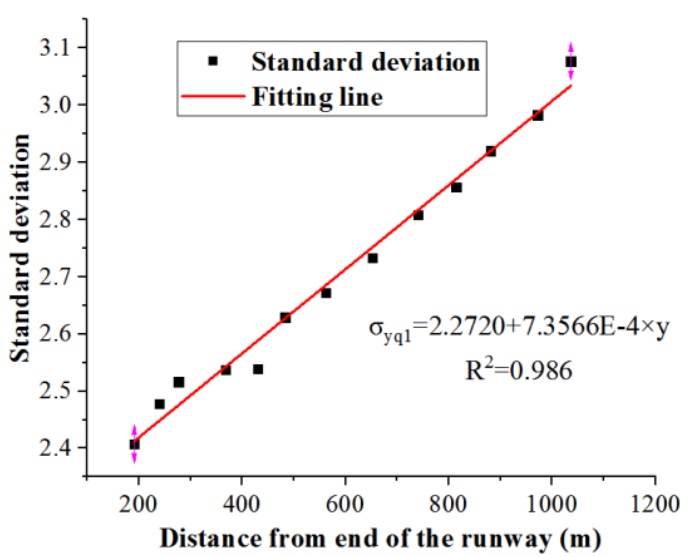

(b)

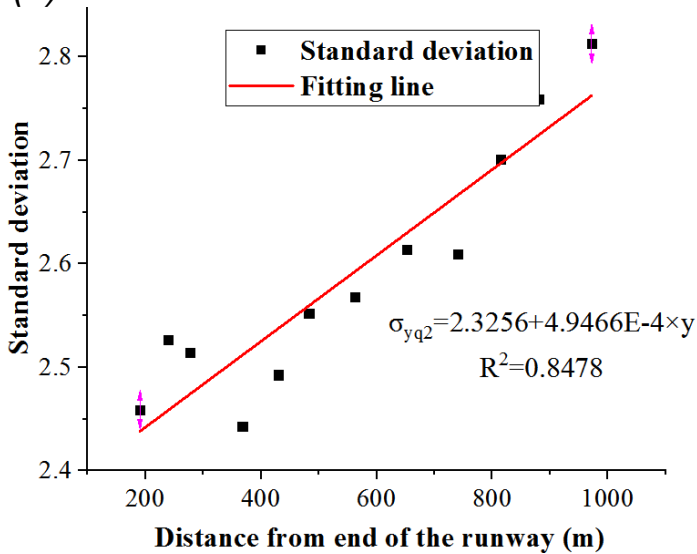

(b) Fitting equation and curve of standard deviation for left and right take-off tracks

Fig. 7 - Fitting equation and curve of standard deviation for take-off track volume of two aircrafts

The take-off wheel coverage of two aircrafts recorded by equipment No. 14 to No.17 was not more than 50 times. There are not enough data to acquire the statistics regulation of these cross sections. As shown in Figure 7, Mean value of the average, $-11.603 \mathrm{~m}$ and $9.528 \mathrm{~m}$ were used to illustrate the traffic volume of close to the flat area and away from the flat area. What is more, similar to the single aircraft, the standard deviation increases gradually with the increase of the flight distance. It is interesting that the deviation which close to flat area had good linear fitting with high $\mathrm{R}$-square of 0.986 , while the deviation which away from the flat area had poor linear 
fitting with R-square of 0.8478 . The interference between aircraft skidding may led to the fluctuations.

$$
\begin{gathered}
\mu_{y q 1}=-11.603 \\
\mu_{y q 2}=9.528 \\
\sigma_{y q 1}=2.2720+7.3566 \times 10^{-4} \times y \\
\sigma_{y q 2}=2.3256+4.9466 \times 10^{-4} \times y
\end{gathered}
$$

The wheel-track distribution of the middle point of the main landing gear for two aircrafts can be expressed as:

$$
\begin{aligned}
& f_{X q 1}(x, y)=\frac{1}{\sigma_{y q 1} \sqrt{2 \pi}} e^{-\frac{\left(x-\mu_{y q 1}+0.106\right)^{2}}{2 \sigma_{y q} 1^{2}}} \\
& f_{X q 2}(x, y)=\frac{1}{\sigma_{y q 2} \sqrt{2 \pi}} e^{-\frac{\left(x-\mu_{y q 2}+0.106\right)^{2}}{2 \sigma_{y q 2^{2}}}}
\end{aligned}
$$

\section{LONGITUDINAL STATISTICAL REGULATION OF ARTV}

The design of a runway length is determined by the accelerate-stop distance associated with an aborted take-off under the most adverse environmental conditions. For the majority of the airports, the runway length is surplus, which will result in that ARTV cannot cover the entire pavement. Longitudinal passage factor is the ratio of flight sorties passing through a certain crosssection to the total flight sorties and can be calculated by the following formula:

$$
f_{Y}(y)=\frac{N_{y}}{N}
$$

Where $N_{y}$ is the flight sorties passing through a certain cross-section, $N$ is the total flight sorties.

\section{Longitudinal traffic volume of landing}

The tire marks in the middle of the runway reflect that the landing point of the aircraft is basically within the test range of the first 7 equipment. Remove the days of occasional damage, the longitudinal passage factor of landing in each cross-section is calculated as shown in Table 5.

It can be seen from the Figure 8 that all aircrafts have landed and skidded after the 7th cross-section. That is to say, the longitudinal passage factor identically equal to 1 before the aircraft leaves the runway at the linking taxiway. Polynomial fitting of longitudinal passage factor along y direction can be obtained as shown in Figure 8. 


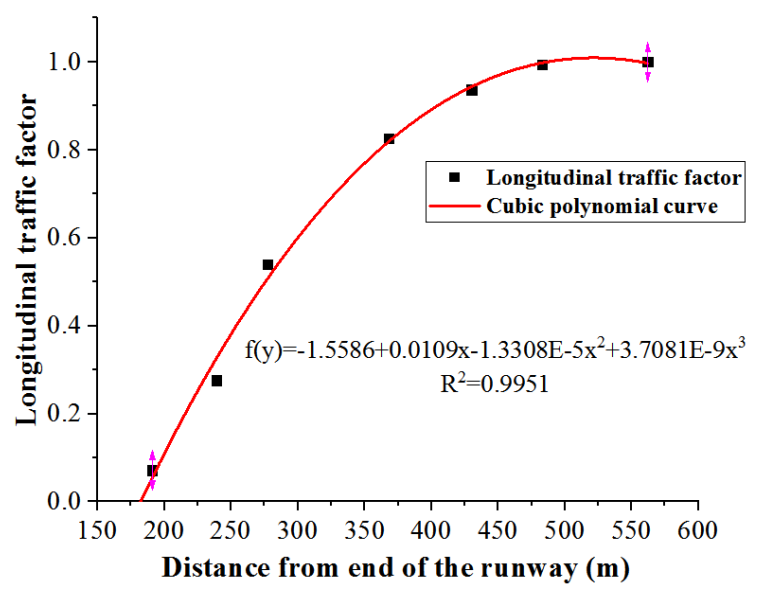

Fig. 8 - Fitting equation and curve of landing longitudinal passage factor

The Piecewise function (14) is adopted to represent the longitudinal passage factor of the whole runway

$$
f_{Y I}(y)=\left\{\begin{array}{ccc}
0 & , & y<180.95 \\
-1.5586+0.0109 y-1.3308 E-5 y^{2}+3.7081 E-9 y^{3} & , & 180.95<y \leq 459.65 \\
1 & , & y>459.65
\end{array}\right.
$$

\section{Longitudinal traffic volume of single-aircraft take-off}

When a single aircraft takes off, the beginning positions are basically at the runway take-off line, and the longitudinal distribution of the take-off point can be ignored. Through observation and statistics, it is found that there are little aircraft take off before the 10th cross-section. In other words, the departure point of the aircraft is basically located at the equipment No. 10 to No. 17 .

Figure 9 shows good linear fitting of the longitudinal passage factors along the runway, which can be express by the following piecewise function (15).

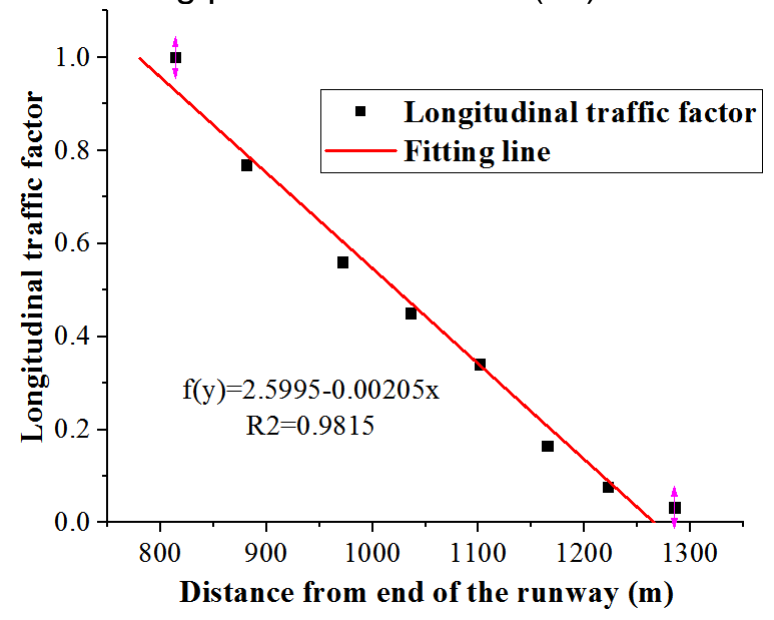

Fig. 9 - Fitting equation and curve of longitudinal passage factor for single aircraft take-off 


$$
f_{\text {Yq单 }}(y)=\left\{\begin{array}{ccc}
1 & , & 150<y \leq 780.24 \\
2.5995-0.00205 y & , & 780.24<y \leq 1268.05 \\
0 & , & y>1268.05
\end{array}\right.
$$

\section{Longitudinal traffic volume of dual-aircrafts take-off}

It has been known that the take-off point is also basically at the runway take-off line, similar to single-aircraft take-off. The longitudinal distribution of the beginning point can be ignored.

Through observation and statistics, it was found that the dual-aircrafts left the ground successively after the cross-section of equipment No. 10. direction.

Figure 10 shows the polynomial fitting of dual-aircraft longitudinal passage factor along y

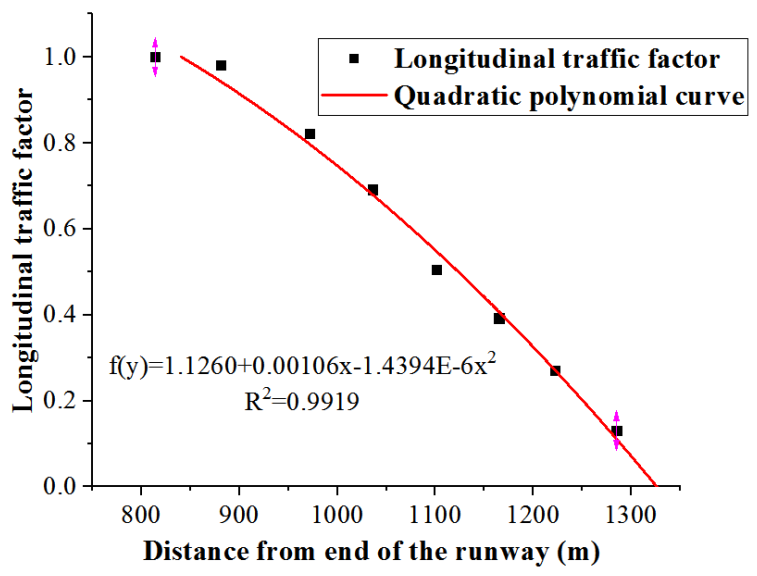

Fig. 10 - Fitting equation and curve of longitudinal passage factor for dual-aircraft take-off

Adopt the following piecewise function (15) to represent the longitudinal passage factor of the whole runway:

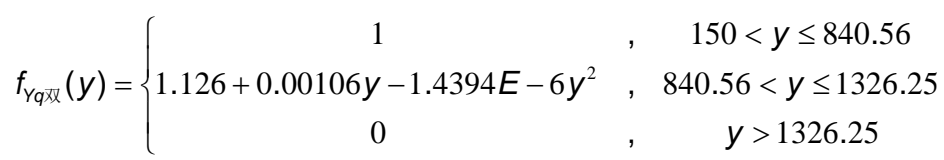

\section{PLANE DISTRIBUTION MODEL OF ARTV}

Previous sections have studied the lateral and longitudinal traffic volume of landing, singleaircraft take-off and dual-aircraft take-off. Normal fitting curves of ARTV were obtained, which reflect the probability of wheel-track migration on each cross-section. Longitudinal passage factor is defined as the probabilistic representation of the total flight sorties passing through a crosssection. The joint distribution of lateral and longitudinal directions represented the traffic volume probability at a certain point of the pavement surface.

The total number of flights operated by the airport in its design life is assumed to be $N$ times, including $N_{\mathrm{s}}$ times of single-aircraft take-off and $N_{d}$ times of dual-aircraft take-off, where $N=N_{\mathrm{s}}+2 N_{d}$. Take-off and landing ratio of flight sorties at one side to the other is $a: b(a+b=1$ ). The ARTV of landing, single-aircraft take-off and dual-aircraft take-off can be represented by Eq. (17), Eq. (18), Eq. (19) and Eq. (20) respectively. 


$$
\begin{gathered}
N_{x, y l}=a N \cdot f_{X l}(x, y) \cdot f_{Y l}(y)+b N f_{X l}(x, L-y) f_{Y l}(L-y) \\
N_{x, y q \mathrm{~s}}=a N_{\mathrm{s}} \cdot f_{X q \mathrm{~s}}(x, y) \cdot f_{Y q s}(y)+b N f_{X q \mathrm{~s}}(x, L-y) f_{Y q \mathrm{~s}}(L-y) \\
N_{x, y y d 1}=a N_{\mathrm{d}} \cdot f_{X q 1}(x, y) \cdot f_{Y q \mathrm{~d}}(y)+b N_{\mathrm{d}} f_{X q 1}(x, L-y) f_{Y q \mathrm{~d}}(L-y) \\
N_{x, y q \mathrm{~d} 2}=a N_{\mathrm{d}} \cdot f_{X q 2}(x, y) \cdot f_{Y q \mathrm{~d}}(y)+b N_{\mathrm{d}} f_{X q 2}(x, L-y) f_{Y q \mathrm{~d}}(L-y)
\end{gathered}
$$

The traffic volumes of main landing gear left wheel were calculated by the upper planar distribution model. It is necessary to add right wheel traffic volume to the formulas to get the whole coverage. Neglect the effect of aircraft drift and wheel roll, the normal distribution mean at the center of right wheel needs to add the width of the two main landing gears, while the standard deviation remains unchanged.

It is known that the take-off and landing sorties of this airport support aircraft in the design life are 100,000 times. The probability of taking off and landing at one side to the other is 7:3 and the take-off ratio of single-aircraft to dual-aircraft is $1: 3$. The airport had a runway length of $2800 \mathrm{~m}$, and width of $60 \mathrm{~m}$. Assumed that all aircrafts leave the runway from the contact channel (the longitudinal coordinates at both ends are $300 \mathrm{~m}$ and $2500 \mathrm{~m}$ respectively). Based on the wheel track test statistical regulation and the planar distribution model, the coverage of the main landing gear wheels under three states of landing, single-aircraft take-off and dual-aircraft take-off can be obtained, as shown in Figure11, Figure12 and Figure 13 respectively.
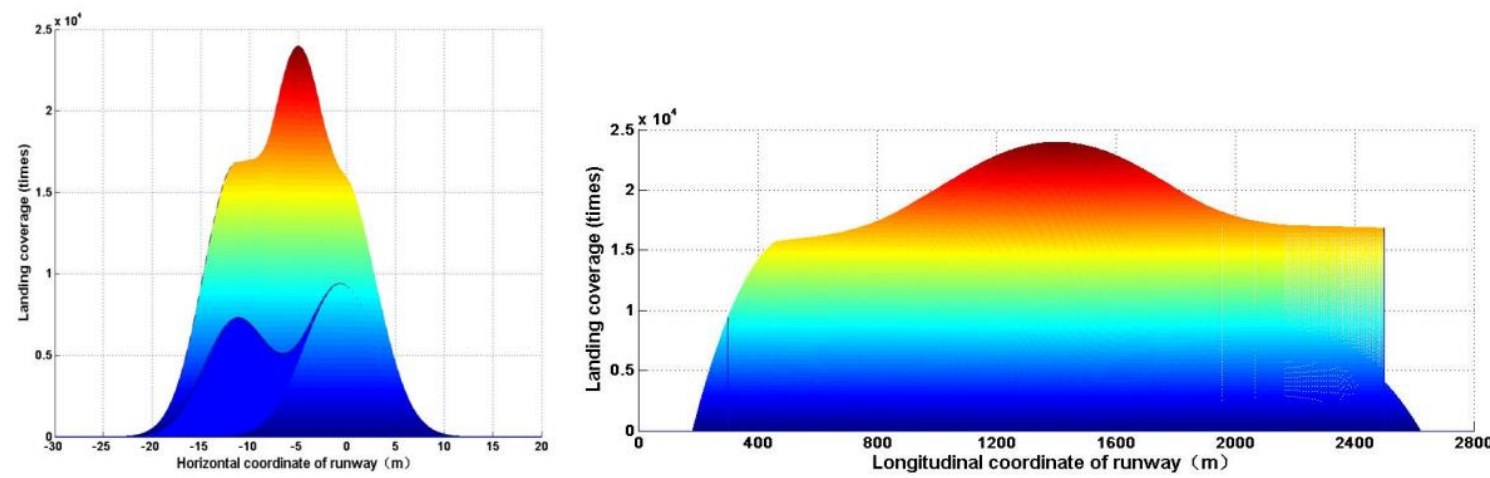

Fig. 11 - Traffic distribution surface of landing
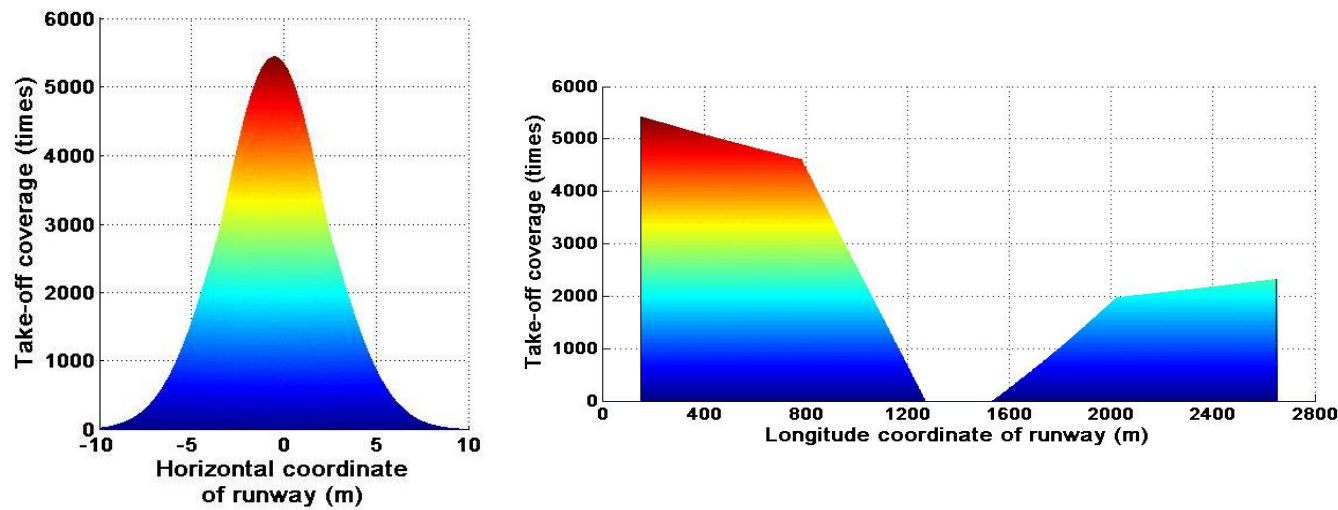

Fig. 12 - Traffic distribution surface of single-aircraft take-off 

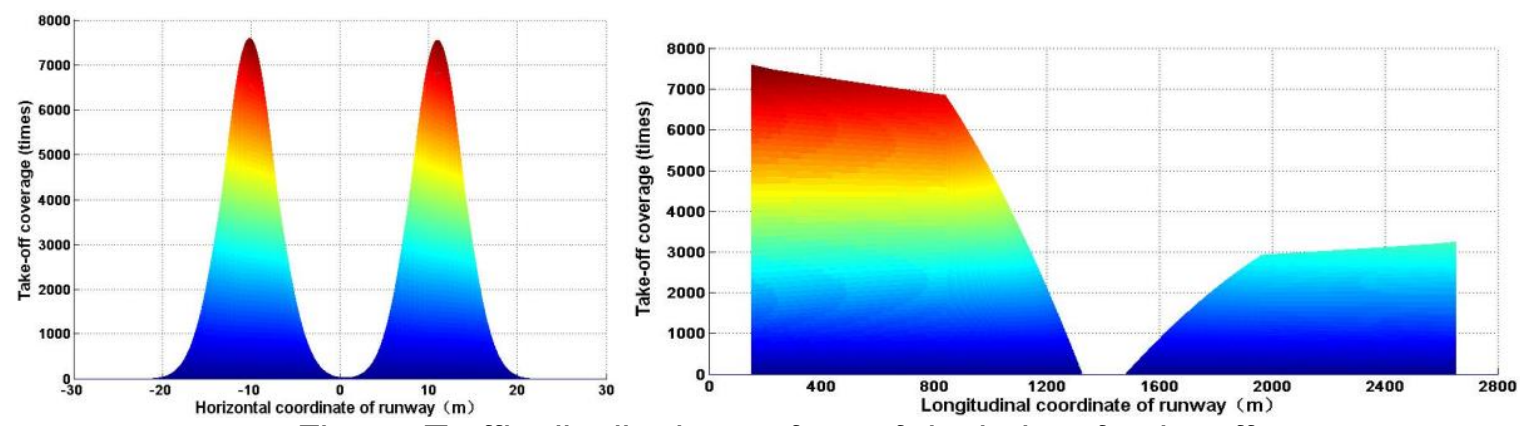

Fig. 13 Traffic distribution surface of dual-aircraft take-off

As seen in Figure 11 to Figure13, it is shown that the wheel tracks distributed throughout the runway. Coverage times at every point of the pavement can be clearly calculated using the above model, with maximum value of 23986 times for landing, 5423 times for single-aircraft takeoff, 7575 times and 7535 times for dual-aircraft take-off near the flat area and for away from the flat area. If the lateral distribution of the wheel track is calculated according to the specification, with an average value of $0.02 \mathrm{~m}$ and a standard deviation of $2.83 \mathrm{~m}$, neglecting the longitudinal distribution, the ARTV is shown in following Figure 14.

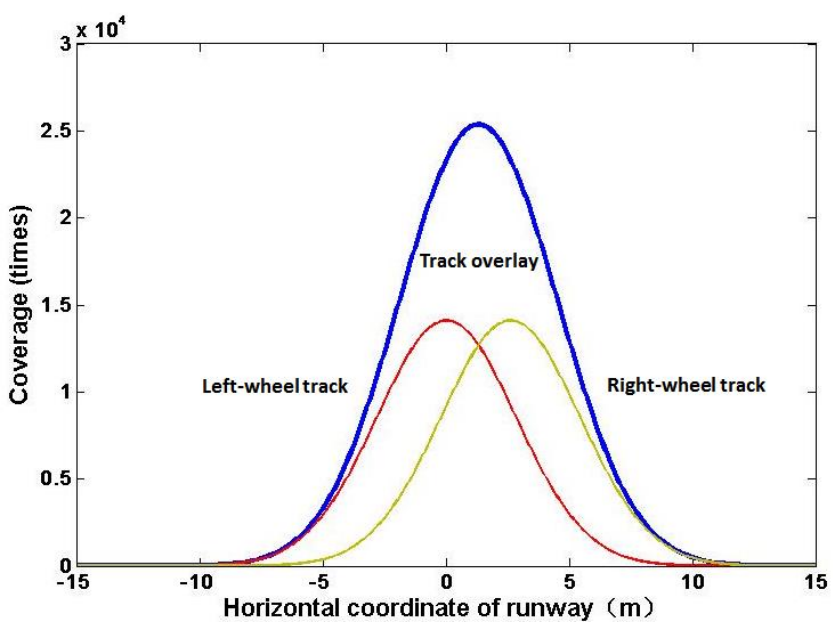

Fig. 14 - Traffic volume curve of lateral distribution

As can be seen from the figure above, the traffic volume curve only considering the transverse distribution is one case of the planar distribution model, which has not considered the aircraft's take-off and landing point, taxiing offset and longitudinal passage probability of each cross-section. It can be calculated that the maximum coverage times of the traffic volume distribution curve are 25,370 times. Compared with the above planar model, it is found that without considering the longitudinal distribution of APTV will make an excessive estimate of the traffic volume and more conservative for the pavement thickness design. What is more, the planar model can also be used to determine the width of airport runway based on runway risk probability. These are also our future research directions.

\section{CONCLUSIONS}

This paper pointed out that there are not only lateral distributions, but also longitudinal distributions of ARTV based on the analysis of its characteristics. An airport runway traffic 
measurement system was developed, which adopted laser testing technology to test the wheel track distribution in landing, single-aircraft take-off and dual-aircraft take-off. The regulation of lateral distribution of wheel tracks was analyzed statistically. The longitudinal passage factor was proposed to illustrate the longitudinal distribution of ARTV. Then, the planar distribution model of ARTV was established. The example showed that the planar distribution model could evaluate the coverage times of every point on the pavement. In addition, by comparing with traffic volume calculation method in current design specification, it was found that only considering the lateral distribution of traffic volume will make the pavement design more conservative.

The model proposed in this paper developed the traffic volume calculation method from transverse distribution curve to planar distribution surface, without considering the load of different aircraft weight. Combined with the planar distribution of load, it can provide the traffic volume basis for pavement segmentation design and establish the pavement design method based on the cumulative damage surface.

\section{ACKNOWLEDGMENTS}

The authors give special thanks to Tianjing Yangcun Airport for their supply of the test site.

\section{REFERENCES}

[1] Richard G. Ahlvin Origin of Developments for Structural Design of Pavements Report No. GL-91-26

U.S.Army Corps of Engineers, Waterways Experiment Station, Vickburg, MS.1991.

[2] Zhang Yaohua. Study on Evaluation System of cement concrete pavement of airport. Tianjin: Tianjin University, 2007 (in Chinese).

[3] Paul Stephen Dempsey. Airport Planning \& Development Handbook—a Global Survey. USA New York: McGraw-Hill, 1999.

[4] Vedros, P. J. "Study of Lateral Distribution of Aircraft Traffic on Runways," Miscellaneous Paper No. 4-369, Jan 1960, U. S. Army Engineer Waterways Experiment Station, CE, Vicksburg, Miss.

[5] Brown,D.N.and Thompson,O.O. Lateral Distribution of Aircraft Traffic, Miscesllaneous Paper S-7356,U.S.Army Corps of Engineers, Waterways Experiment Station, Vickburg, MS.1973

[6] Hosang V. A. Field survey and analysis of aircraft distribution on airport pavements[R]. Washington , D. C. , USA: FAA, 1975.

[7] MINCAD Systems Pty. Ltd. APSDS 4 User Manual Airport Pavement Structural Design System. Australia, September 2000.

[8] FAA, the Boeing Company. Statistical Extreme Value Analysis of JFK Taxiway Centerline Deviations for 747 Aircraft. FAA/Boeing Cooperative Research and Development Agreement 01-CRDA-0164, 2003.11.

[9] FAA, the Boeing Company. Statistical Extreme Value Analysis of ANC Taxiway Centerline Deviations for 747 Aircraft. FAA/Boeing Cooperative Research and Development Agreement 01-CRDA-0164 , 2003.11.

[10] U.S. Department of Transportation, Federal Aviation Administration. Airport Pavement Design and Evaluation, AC No: 150/5320-6E. U.S. Department of Transportation, Federal Aviation Administration, 2009.9.

[11] U.S. Department of Transportation, Federal Aviation Administration. Airport Pavement Design and Evaluation, AC No: 150/5320-6F. U.S. Department of Transportation, Federal Aviation Administration, 2016.

[12] U.S. Department of Transportation, Federal Aviation Administration. Standardized Method of Reporting Airport Pavement Strength - PCN (DRAFT), AC No: 150/5335-5A. U.S. Department of Transportation, Federal Aviation Administration.

[13] CROW.Guideline on PCN Assignment in the Netherlands. CROW-report 05-06, Netherlands: Galvanistraat, 2005.8. 
[14] Japanese Transport Ministry. Essentials and Design Examples of Airport Pavement Design. Port Airport Construction and Design Technical Service Center, 2008

[15] Airport Pavement Design and Maintenance, Bagu Haogao, Tianbo Translation, China Communications Press, 2015.

[16] G.P. Cen, S. Lu, G. Hong. Research on reliability design method of airport runway width. Science and Technology Guide, 2014, 32 (22): 47-51

[17] H. Fang, L.C. Cai, L.L. Zhang, Z. Liu, Z.H. Wang, Traffic volume analysis of airport pavement based on traffic coverage, Sichuan Architectural Science Research, 2013;39(1)(2013): 60-63.

[18] Z.H. Wang, L.C. Cai, Q.K. Gu. The cumulative damage optimization model of airport rigid pavement considering load stress distribution. Journal of civil engineering, 2011 (11): 151-158.

[19] Chinese specifications for asphalt pavement design of civil airports: $\mathrm{MH} / \mathrm{T}$ 5010-2017, PR China (Beijing): Civil Aviation Administration: 2017.

[20] Q. Li, H.D. Zhao, Z.K. Yao. Calculation Method of the plane load frequency based on channel response, Journal of Tongji University (NATURAL SCIENCE EDITION), 2008;36 (12): 1637- 1641.

[21] X.P. Lin. Theory and design method of airport runway overlay under complex conditions. Ph. D. Thesis, Tongji University, China, 2007.

[22] L. Lei, H.D. Zhao, C. Wu. Comparative analysis of horizontal distribution test system of aircraft wheel track. Traffic engineering, 2012, 10:63-68.

[23] L. Lei, research on the lateral distribution rule of runway wheel track of civil airport [D]. Master's thesis of tongji university,2013.05.

[24] E.H. Shi, spatial structure response of asphalt pavement surface under non-uniform contact stress [D]. Master's thesis of tongji university, March 2015

[25] J. Yuan, E.H. Shi, L. Lei, X.P. Shao, Lateral Deviation Pattern and Method of Aircraft Wheel Path on Shanghai Hongqiao International Airport, Journal of Civil Aviation University of China, 2015,33(2):1-6

[26] L.K. Ma, H. D. Zhao, Z. M. Du, Z. A. Chen. Cumulative damage calculation of flexible pavement considering aircraft operation characteristics, Journal of Chongqing Jiaotong University (Natural Science), 2017;36 (9): 38-43.

[27] Cen Guoping, Lu Song, Hong Gang, Lin Kexin, Xu Feng. Research on Reliability Design Method of Airport Runway Width, Science \& Technology Review, 2014,32(22):47-51.

[28] L.C. Cai, H.F. Wang, L.L. Zhang, P.F. Wang. A residual life prediction model for airport pavement based on cumulative damage, Journal of Traffic and Transportation Engineering, 2014;14 (4) : 1-6. 